quartz and mullite in the silicate glass phase), determined by thermal history of the particles during combustion. Solid microspheres are formed from the hollow particles simply by fusion at higher temperatures.

Unless the Moon has had sedimentary processes, therefore, the similarity of moon dust with the major part of pfa must be limited to the presence, in both, of silicate glass spheres and not extend to the details of particle formation. High velocity streams of molten glass can also break up into microspheres.

$$
\text { Yours faithfully, }
$$

Etwall, Derby.

D. J. ThORNe

(Formerly: The BCURA, Leatherhead.)

The BCURA, Leatherhead.

${ }^{1}$ Watt, J. D., and Thorne, D. J., J. Appl. Chem., 15, 585 (1965).

${ }^{2}$ Thorne, D. J., and Watt, J. D., J. Appl. Chem., 15, 595 (1965).

${ }^{3}$ Watt, J. D., and Thorne, D. J., J. Appl. Chem., 16, 33 (1966).

\section{No Gulf at Cambridge}

SiR,-As members of the Medical Research Council Laboratory of Molecular Biology and of the University of Cambridge, we are concerned by your statement in the article "Dog Wags Tail" (Nature, 223, 989; 1969) that there is a gulf between us. It is in the interest of the subject and in the interest of graduate and undergraduate students in Cambridge that the two institutions should work closely together, and we think they do. Naturally they have differences of function and emphasis, but we all value immensely the ties in both research and teaching that link us. Many members of each institution have worked in the other. Members of the Laboratory of Molecular Biology teach undergraduates in the university departments of physics, biochemistry and physiology. Many members of the laboratory hold college fellowships. Over twenty graduate students are working for their $\mathrm{PhD}$ degrees in the laboratory. There is scientific collaboration between the laboratory and the departments of chemistry, biochemistry, physiology and pharmacology. The laboratory and the Institute of Theoretical Astronomy share a large computer. We are glad that your statement gives us an opportunity for making these facts widely known.

$$
\text { Yours faithfully, }
$$

$$
\begin{aligned}
& \text { A. S. V. Burgen } \\
& \text { H. B. F. Dixon } \\
& \text { A. L. HodGKin } \\
& \text { N. F. MotT } \\
& \text { ALISON A. Newton } \\
& \text { M. F. PERUTZ } \\
& \text { F. SANGER } \\
& \text { TodD } \\
& \text { F. G. Young }
\end{aligned}
$$

Cambridge.

\section{University News}

The title of professor of mathematical physics has been conferred on Dr L. Pincherle in respect of his post at Bedford College, University of London.

'The title of professor of applied zoology has been conferred on Dr M. J. Way in respect of his post at the Imperial College of Science and Technology, University of London.

Professor D. J. Alner, head of the department of chemistry, has been elected. Pro-Vice-Chancellor of the City University, London.

\section{Appointments}

Dr H. W. Springer, Assistant Secretary-General (Education) at the Commonwealth Secretariat, has been appointed Secretary-General of the Association of Commonwealth Universities.

Professor J. F. Fowler has been appointed director of the British Empire Cancer Campaign for Research's Research Unit in Radiobiology at Mount Vernon Hospital, Northwood, Middlesex. He succeeds Dr O. C. A. Scott, who retires on December 30.

\section{Announcements}

The Lalor Foundation, whose principal aim is to assist qualified investigators working on scientific and medical research projects concerned with uterine physiology, invites applications for its postdoctoral research awards for 1970. The awards are open to all nationalities, and the upper age limit is 41 years. The work may be carried out at the applicant's own institution or elsewhere. Further information may be obtained from: The Lalor Foundation, 4400 Lancaster Pike, Wilmington, Delaware 19805 , USA.

Erratum. In the article "Symmetry Breaking Instabilities in Biological Systems" by Prigogine, Lefever, Goldbeter and Herschkowitz-Kaufman (Nature, 223, 913; 1969), the following changes are necessary. In line 11 , read "can" instead of "cannot". In equations $2,3,7$ and 8 , the denominators in the last term should be " $\partial \mathrm{r} 2$ " " and not " $\partial \tau^{2}$ ". On page 914 , right-hand column, line 14 read " $C_{3}$ " instead of " $C_{6}$ ". In equations $6-15$, the suffixes to various " $k$ " terms were unfortunately written in the line: " $k-1$ " should read " $k_{-1} "$, " $k+2$ " should read " $k_{+2}$ " and so on. Finally, equation 15 should read:

$$
v_{1}=\sqrt[\gamma]{\left(\frac{k_{-2}+k_{+2}}{k_{+1} \cdot k_{+2}}\right)\left(\frac{k_{-3}}{k_{+3}}\right) \frac{k_{2}{ }^{\gamma+1}}{e_{0}} \cdot \frac{D_{A_{3}}}{D_{A_{2}}}(\sqrt{\gamma}-1)^{2}}
$$

\section{International Meetings}

October 15, Giant Mouldings, London (C. W. Oakhill, 139 Broomfield Avenue, Palmers Green, London N13). March 2-6, Automatic Control in Space, Toulouse (Ing. H. Desmoutier, LAAS, BP 4036, 31 Toulouse 04, France).

March 2-6, Engineering Design Show and Conference, Brighton (Miss L. Harvey, Business Conferences and Exhibitions, Ltd, Mercury House, Waterloo Road, London SE1).

March 4-6, Fundamental Cancer Research, Houston (F. Goff, Special Projects, M. D. Anderson Hospital and Tumor Institute, University of Texas, Houston, Texas 77025, USA).

March 9-13, Fast Breeder Reactors, Vienna (International Atomic Energy Agency, Kärtner Ring 11, A-1010 Vienna, Austria).

March 9-13, Use of Isotopes in Hydrology, Vienna (IAEA, Kärtner Ring 11, A-1010 Vienna, Austria).

March 9-14, Primary Radiation Effects in Chemistry and Biology, Argentina (Dr M. A. Molinari, Comision Nacional de Energia Atomica, Avenida del Libertador 8250, Buenos Aires (S. 29), Argentina).

March 11-13, Scintillation and Semi-conductor Counter, Washington (Mr D. C. Cook, US Naval Research Laboratory, Code 7640, Washington DC 20390, USA). March 13-17, Plant Analysis and Fertilizer Problems, Tel Aviv (Professor R. M. Samish, e/o National and University Institute of Agriculture, POB 15, Rehovoth, Israel). 